\title{
Seasonal to interannual climate predictability in mid and high northern latitudes in a global coupled model
}

\author{
Torben Koenigk · Uwe Mikolajewicz
}

Received: 5 November 2007 / Accepted: 30 April 2008/Published online: 27 May 2008

(C) The Author(s) 2008

\begin{abstract}
The upper limit of climate predictability in mid and high northern latitudes on seasonal to interannual time scales is investigated by performing two perfect ensemble experiments with the global coupled atmosphere-oceansea ice model ECHAM5/MPI-OM. The ensembles consist of six members and are initialized in January and July from different years of the model's 300-year control integration. The potential prognostic predictability is analyzed for a set of oceanic and atmospheric climate parameters. The predictability of the atmospheric circulation is small except for southeastern Europe, parts of North America and the North Pacific, where significant predictability occurs with a lead time of up to half a year. The predictability of $2 \mathrm{~m}$ air temperature shows a large land-sea contrast with highest predictabilities over the sub polar North Atlantic and North Pacific. A combination of relatively high persistence and advection of sea surface temperature anomalies into these areas leads to large predictability. Air temperature over Europe, parts of North America and Asia shows significant predictability of up to half a year in advance. Over the icecovered Arctic, air temperature is not predictable at time scales exceeding 2 months. Sea ice thickness is highly predictable in the central Arctic mainly due to persistence and in the Labrador Sea due to dynamics. Surface salinity is highly predictable in the Arctic Ocean, northern North Atlantic and North Pacific for several years in advance. We compare the results to the predictability due to persistence and show the importance of dynamical processes for the predictability.
\end{abstract}

T. Koenigk $(\bowtie) \cdot$ U. Mikolajewicz

Max-Planck-Institut für Meteorologie,

Bundesstraße 53, 20146 Hamburg, Germany

e-mail: torben.koenigk@smhi.se
Keywords Predictability · Mid and high latitude climate · Seasonal to interannual variability .

Global coupled atmosphere-ocean modeling .

Coupled atmosphere-ocean-sea ice processes

\section{Introduction}

Knowledge of future weather and climate states would be of great value for society. Unfortunately, numerical weather predictions are limited to several days or a few weeks by the chaotic nature of the atmosphere (Lorenz 1963; Mu et al. 2002), which leads to the rapid growth of small errors in initial conditions. Hence, longer predictions into the future are only possible for the mean state and the statistics of weather in a certain time period. Seasonal to interannual climate predictions are promising if their response to boundary forcing is large enough to overcome the uncertainties of the initial conditions. The predictability of most atmospheric variables improves with increasing time averaging interval at the expense of losing information about individual weather and climate events (Reichler and Roads 2003). The most prominent example of seasonal forecast is El Nino-Southern Oscillation (ENSO, e.g. Keenlyside et al. 2005; Tang et al. 2006; Zheng et al. 2006). However, ENSO affects mainly tropical and Pacific regions. Climate in Arctic regions does not show any or only weak teleconnections to ENSO. The response of the extra-tropical North Atlantic region to ENSO is still under debate but is obviously much weaker than in the Pacific. (Van Oldenborgh 2005a; Compo and Sardeshmukh 2004; Pozo-Vasquez et al. 2005). Motivated by the strong impact of the North Atlantic Oscillation (NAO) on North Atlantic and European winter climate, considerable effort has been devoted to improving the prediction of the sign of next 
winter's NAO-index. However studies by Saunders and Qian (2002), Müller et al. (2005) and Kushnir et al. (2006) showed that the predictability of the NAO-index of the following winter or the following month is rather small. Peng et al. (2005) analyzed the impact of tropical Atlantic SST and the "horse shoe pattern" on the NAO but found only a slightly increased predictability compared with the climatologically means. Other studies analyzed the atmospheric response on North Atlantic sea surface temperature (SST) more generally and tried to find seasonal predictabilities (e.g. Lin and Derome 2003; Frankignoul et al. 2003; Friedrichs and Frankignoul 2003). They all found a significant predictability of atmospheric circulation in spring but no or only weak signals in the other seasons. Rodwell et al. (2004) analyzed the impact of Atlantic Ocean SST on climate in different models and found similar patterns in all models. They suggested that the response of the extra-tropical Atlantic region is mainly associated with Caribbean and tropical Atlantic SST anomalies. An overview of Atlantic climate variability and predictability is given by Hurrell et al. (2006).

Predictability on decadal time scales focuses mainly on the meridional overturning circulation (MOC) and lowfrequency SST variations (Latif et al. 2006). Pohlmann et al. (2004) found evidence for SST predictability in the North Atlantic in a global coupled atmosphere-ocean-sea ice model on a decadal to multi-decadal time scale. Collins and Sinha (2003) performed ensemble experiments with a coupled climate model and found a significant predictability of the MOC for the following two decades. In a recent paper, Collins et al. (2006) analyzed ensemble experiments of five different coupled atmosphere-ocean models. They related decadal variability of the MOC to surface temperature variability in the North Atlantic and found both parameters potentially predictable.

In this study, we performed a large number of perfect model experiments with a global coupled atmosphereocean-sea ice model (AOGCM) to analyze the potential predictability at seasonal to interannual time scales. Besides the fact that we present a unique and comprehensive study of mid and high latitude climate predictability, predictabilities with lead times between half a year and a few years are not captured by most previous studies concerning mid and high northern latitude climate. We focus mainly on atmospheric and near surface oceanic and atmospheric variables in mid and high latitudes. This includes in particular sea ice whose predictability was poorly analyzed so far. The article is organized as follows. In the following chapter we describe briefly our model. Chapter three explains the experimental design and methodology. In chapter four, we present our results and in the last chapter our results are summarized and conclusions are drawn.

\section{Model description}

The model used in this study is the Max-Planck-Institute for Meteorology global atmosphere-ocean-sea ice model consisting of the atmosphere model ECHAM (ECmwf HAMburg) and the ocean model MPI-OM (Max-PlanckInstitute Ocean Model). The atmosphere model ECHAM5 (Roeckner et al. 2003) is run at T31 resolution, which corresponds to a horizontal resolution of about $3.75^{\circ} \times 3.75^{\circ}$ It has 19 vertical levels up to $10 \mathrm{hPa}$. The ocean model MPI-OM (Marsland et al. 2003; Jungclaus et al. 2006) includes a Hibler-type dynamic-thermodynamic sea ice model with viscous-plastic rheology (Hibler 1979). The ocean grid is based on an Arakawa C-grid and allows for an arbitrary placement of the grid poles. In this setup, the model's North Pole is shifted to Greenland and the South Pole is placed in the center of Antarctica. This approach avoids the numerical singularity at the North Pole. It has the additional advantage of a relatively high resolution in the deep-water formation regions near Greenland and in the Weddell Sea. The grid spacing varies between about $30 \mathrm{~km}$ around Greenland and $368 \mathrm{~km}$ in the tropical Pacific. The model has 40 vertical levels.

The atmosphere model and the sea ice-ocean model are coupled by the OASIS coupler (Valcke et al. 2003). The coupler transfers fluxes of momentum, heat, and freshwater from the atmosphere to the ocean and performs the interpolation onto the ocean grid. It also transmits sea surface temperature, sea ice thickness and concentration, snow thickness and surface velocity from the ocean to the atmosphere. The climate model includes a river runoff scheme (Hagemann and Dümenil 1998; Hagemann and Dümenil-Gates 2003). The river runoff is transferred to the ocean together with the difference of precipitation and evaporation. Glacier calving is included such, that any snow falling on Greenland and Antarctica is instantaneously transferred to the nearest ocean grid point. Hence, the mass balance of glaciers and ice sheets is not accounted for. In the coupled model, no flux adjustment is used.

The model we use here is the coarse resolution version of the model version that has been used for the IPCC-AR4 simulations (e.g. Koenigk et al. 2007; Jungclaus et al. 2006). Due to the coarser resolution, the model climate differs for certain parameters and regions slightly from the high resolution version. Key components of the climate of this model version are shown in Fig. 1. The SLP agrees well with observations and reanalysis in the North Atlantic sector and over most parts of Europe, Asia and North America. However, the Aleutian Low is too weak and the Pacific subtropical high is too pronounced. Over the central Arctic, the pressure is slightly overestimated. The annual mean air temperature shows the typical discrepancies from the zonality but is generally slightly too cold in high 


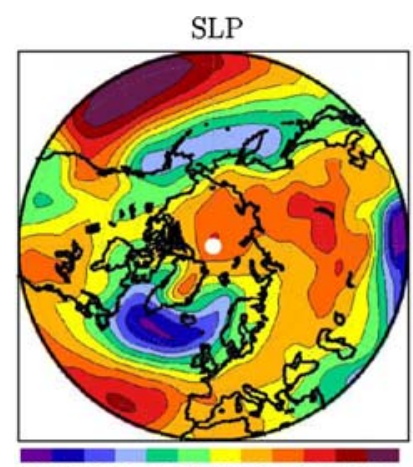

100610101014101810221026

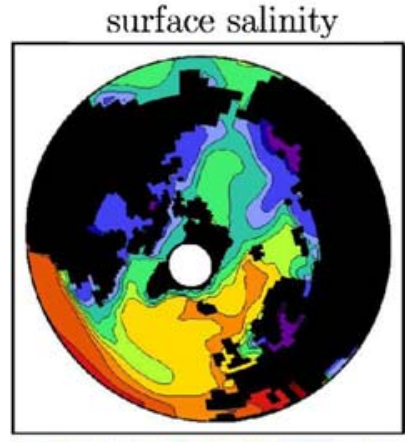

$\begin{array}{llllll}20 & 30 & 32 & 34 & 36 & 38\end{array}$
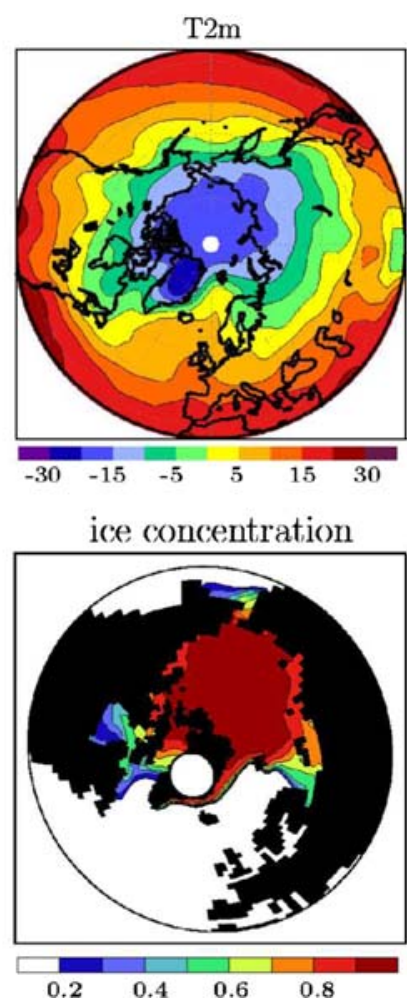

Fig. 1 Model climate: annual mean SLP (in hPa), $2 \mathrm{~m}$ air temperature (in Kelvin), $6 \mathrm{~m}$ salinity (in psu) and sea ice concentration (in parts) in the control integration

latitudes by 1-3 K. In the Barents Sea, air temperature is up to $5 \mathrm{~K}$ too cold. This large negative bias is due to too much sea ice in this area. However, the Barents Sea is mainly ice-free during summer. Compared to satellite data, the ice extends slightly far south into the Labrador Sea and the Greenland Sea. Ice thickness is overestimated at the Siberian coast due to too weak offshore winds, which is a common problem in global coupled atmosphere-ocean-sea ice models. The simulated surface salinity agrees well with the Polar Science Center Hydrographic Climatology (Steele et al. 2001) in most areas of the North Atlantic and the Nordic Seas. Main discrepancy in this area is a too pronounced low-salinity tongue extending from Newfoundland into the Atlantic. In the Arctic Basin, the model captures well the areas of low salinity at the coasts, which is due to the fresh water input of rivers. In the Central Arctic, the surface salinity is slightly too high. The maximal meridional overturning circulation in the North Atlantic reaches about $16 \mathrm{~Sv}$ in the coarse resolution version compared to $22 \mathrm{~Sv}$ in the high resolution version. The first Empirical Orthogonal Function (EOF) of annual mean SLP and $2 \mathrm{~m}$ air temperature between $30^{\circ}$ and $90^{\circ} \mathrm{N}$ in the model and NCEP-reanalyses agree well and explain a similar amount of the total variance (not shown). Altogether, the model version used here realistically simulates

the mean climate and its variability. The use of the coarse resolution model version in this study allowed us to calculate a large number of ensembles.

\section{Experiments and methods}

A 300-year control integration of this model setup is analyzed and two perfect ensemble experiments are performed. Experiment one (EXPJAN) consists of 40 ensemble simulations. The ensembles are initialized from different years of the 300-year control integration because the predictability skill may strongly depend on the initial state (e.g. Palmer 1993; Reichler and Roads 2003). Each ensemble consists of six members and all runs were initialized at 1 st January from slightly perturbed initial conditions and were run for 8 years. For 20 out of 40 ensembles, initial conditions of the ensemble members were constructed by a slight change of the atmospheric diffusion parameter in the first model month. For the remaining 20 ensembles, a small randomly distributed perturbation was added to ocean temperature, salinity and sea ice thickness. However, it turned out that, on the time scales of interest, it does not make any difference where a perturbation, if small enough, is introduced to the system. Therefore, the 40 ensembles are analyzed together in EXPJAN.

The setup of experiment two (EXPJUL) is similar to EXPJAN but consists of 20 ensembles. All runs were initialized at 1st July with a slight perturbation in the atmospheric diffusion parameter.

The predictability of the model climate is analyzed by calculating the prognostic potential predictability (PPP, Pohlmann et al. 2004). The PPP is a measure for the ensemble variance of a climate variable $X$ at time $t$ in relation to its variance in the control run and is defined as:

$\operatorname{PPP}(t)=1-\frac{\frac{1}{N(M-1)} \sum_{j=1, N} \sum_{i=1, M}\left[X_{i, j}(t)-\underline{X}_{j}(t)\right]^{2}}{\sigma^{2}}$

$X_{i, j}$ : run $i$ of ensemble $j, \underline{X}_{j}$ : mean of ensemble $j, N(M)$ : number of ensemble runs (ensemble members), $\sigma^{2}$ : variance of the control run.

A PPP of 1 shows perfect predictability while a value of 0 shows no predictability at all. In this case, the ensemble spread is equal to the variance of the control integration. The 95\% significance level (using an $f$ test) of PPP in EXPJAN varies between values of 0.2 and 0.3 depending on the decorrelation time of the different variables, which also changes with the location of the variable. In EXPJUL, a PPP exceeding 0.24-0.42 is significant at the $95 \%$ level due to the smaller number of ensembles. For most atmospheric variables except for $2 \mathrm{~m}$ air temperature in the central parts of the 
northern North Atlantic and Pacific, the 95\% significance level is near 0.2 and 0.24 in EXPJAN and EXPJUL, respectively. Ocean variables normally have longer decorrelation times and the significance level is slightly higher. PPP in EXPJAN and EXPJUL differ significantly if the PPPdifference exceeds 0.25 (for 1 -year decorrelation time). The results are compared to the predictability gained from persistence of the control integration. This predictability is given by the square of the autocorrelation $\left(r^{2}\right.$ auto $)$. If the correlation with the month before initialization (December in EXPJAN, June in EXPJUL) exceeds the autocorrelation then we take this correlation instead of the autocorrelation. This is mainly the case for seasonal predictabilities and the first-year predictability of sea ice thickness and concentration. In the following, we refer to persistence in both cases. The difference between the potential predictability and persistence is called gain of predictability: $\mathrm{PPPa}=$ PPP $-r_{\text {auto }}^{2}$.

This study concentrates on the predictability of atmospheric and near surface variables, as most areas of the deep ocean do not respond significantly to marginal perturbations at seasonal to interannual time scales. Note, that we analyze the potential predictability of climate in this particular coupled climate model. The predictability shown in this study is based on having a perfect model and having near perfect knowledge of the current state of climate system. Both will of course never be achieved in the real world. Initial conditions are not the only source of uncertainty for predictability but model errors contribute to the uncertainties as well. If a model realistically simulates climate, it can be expected that predictability of real-world climate is always smaller than predictability in perfect ensemble experiments. Thus, the predictability, which is analyzed in our study, can be called upper limit of predictability. It has to be noted that this study analyzes predictability of natural climate variability. External forcing as increased greenhouse gases is not included in this study. Including greenhouse gases may lead to enhanced predictabilities in Arctic regions since future climate change is predicted to be particularly large in the Arctic (Koenigk et al. 2007; Holland and Bitz 2003).

It is also worth noting that analyzing the potential predictability with a coupled model seems to be more realistic than using a SST-forced atmospheric GCM model (van Oldenborgh 2005b).

\section{Results}

\subsection{Predictability in the atmosphere}

\subsubsection{Atmospheric circulation}

Wind, temperature and precipitation are the atmospheric climate variables that affect the majority of people most of all. Hence, the motivation to predict these parameters is particularly large. Figure 2 shows the potential predictability of annual mean SLP (January to December in EXPJAN, July to June in EXPJUL) in the first and second year after initialization in January and July. The predictability patterns of the first year are similar in EXPJAN and EXPJUL. Predictability is significant over southern Europe, southern and central Asia, the northwestern North Pacific and northern North America. PPP is significantly larger over the northwestern Pacific and over Canada/ Alaska in EXPJUL than in EXPJAN. No or only low PPP is found from Greenland over Eurasia to the Bering Sea north of $50^{\circ}-60^{\circ} \mathrm{N}$. Predictability is generally small in the second year in most mid and high latitude regions. The persistence of SLP is very low and explains hence only a small part of the interannual predictability of SLP.

The predictability of seasonal SLP is shown in Fig. 3. The predictability of the first 2 months is relatively good in most areas, which is favored by the small perturbation in the initial conditions. In the following spring, SLP is only significantly predictable over the northern North Pacific, parts of Canada and a region in southwestern Asia. Predictability of the summer season (6-8 months) is quite high over most of mid-latitude continents and exceeds the predictability of spring SLP (although lead time is longer). The predictability of autumn (lead time 9-11 months) is very small in the entire mid and high northern latitudes. PPP of SLP of the first 2 months is higher in most areas in EXPJUL than in EXPJAN. The predictability pattern is similar to the JJA-pattern of EXPJAN although PPP is higher due to shorter lead time. This indicates that both
Fig. 2 Top: potential prognostic predictability of annual mean SLP in the first and second year after start of the simulations in January (left) and July (right)
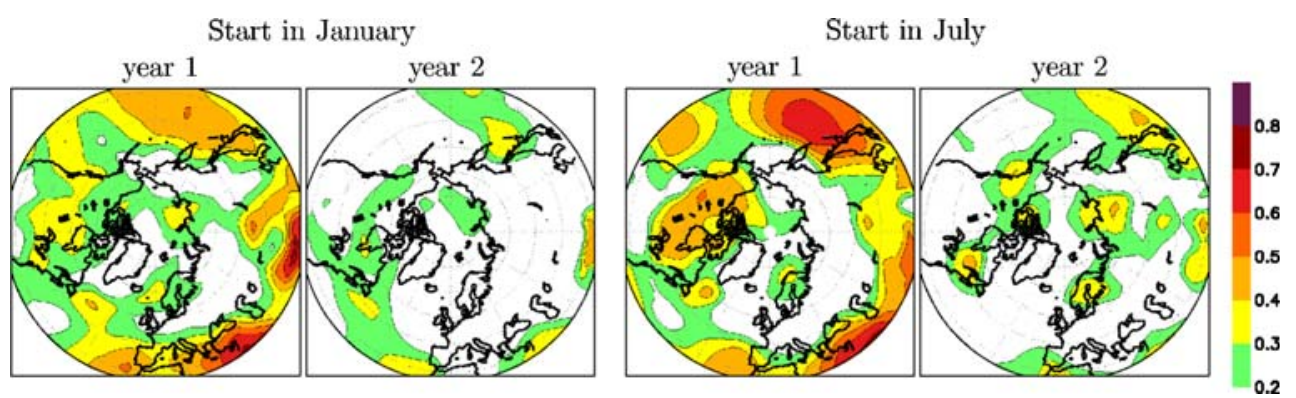
Fig. 3 Top: potential prognostic predictability of seasonal mean SLP for months $1 / 2,3-5,6-8,9-11$ after start of the simulations in January. Bottom: same for initialization in July

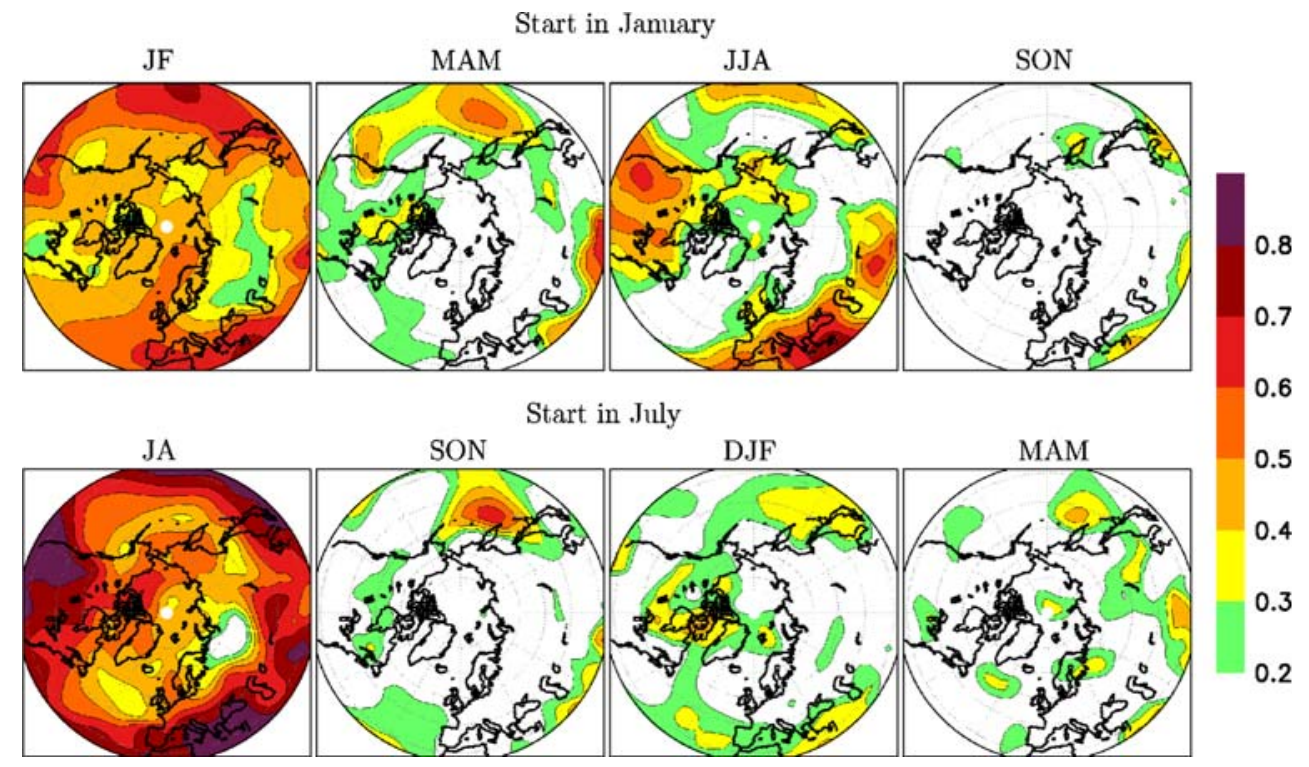

lead time of the prediction and the period to be predicted are important for the predictability. The 3-5 months predictability is very small in EXPJUL except for the northeastern North Pacific. In the following two seasons PPP is below 0.4 but increases in the next summer again (not shown). Generally, predictability of the atmospheric circulation is smallest in autumn, which agrees to sensitivity and predictability studies by Straus et al. (2003) and Quan et al. (2004).

A comparison of the year-1 PPP pattern and seasonal patterns indicate that these timescales are not independent from each other. The mean of the four seasons provides a pattern similar to the year-1 pattern. Similar to the interannual predictability, persistence of seasonal SLP is very small and accounts only in the first 2 months for a considerable amount of predictability.

The high predictability of summer (JJA) SLP in our model can mainly be explained by connection to ENSO. Lag correlation analyses of the control integration show a much larger relation between summer SLP over mid and high latitude continents and preceding tropical Pacific SST than in the other seasons. The same correlations have been performed with NCEP/NCARreanalysis data. The results support the suggestion of a particular strong relation between mid and high latitude summer SLP over continents and surface temperature over the tropical Pacific. It has to be noted that El Nino occurs much more regularly in our model than in observations and much likely too regular. Hence, our climate model might overestimate the predictability caused by ENSO. Van Oldenborgh et al. (2005a) analyzed the seasonal forecast of SLP from the ECMWF seasonal forecasts over a 15-year period. They found a good forecast skill of summer SLP over south eastern
Europe starting the forecast in April. This agrees well with our results.

The predictability of the NAO in our model is relatively small. First year's annual mean predictability is significant in EXPJAN but slightly below 95\% significance in EXPJUL. PPP of winter NAO is 0.5 for the mean of January and February after start in January in EXPJAN and 0.2 for DJF (6-8 months) in EXPJUL. Generally, SLP shows a better predictability over the Azores than over Iceland. In agreement with these results, most studies show, if any, small predictabilities of the NAO (e.g. Fletcher and Saunders 2006; Doblas-Reyes et al. 2003). The predictability of the Arctic Oscillation (AO) is similar to the NAO rather small.

The predictability of the Pacific North American Oscillation (PNA) is slightly higher than those for NAO or AO. PPP of PNA is significant in year 1 in both experiments but not anymore in year 2. Since ENSO influences the PNA (Straus et al. 2003), predictability of the PNA might be overestimated in our simulations. An overview of the main results of this section is presented in Table 1.

\subsubsection{Air temperature}

Variability of the atmospheric circulation is the main source of temperature variations over the continents. Over the oceans and ocean-near regions, variations of SST and sea ice play an important role as well. The predictability of annual mean $2 \mathrm{~m}$ air temperature in the first 2 years is shown in Fig. 4. A strong land-sea contrast dominates the PPP distribution. PPP over the northern North Atlantic and the northern North Pacific is very high and is significant for several years. Largest PPP occurs in the Iceland Basin, where air temperature is mainly governed by SST and 
Table 1 Summary of seasonal to interannual potential predictability of SLP for the annual means of the first 2 years and the means of the months $1 / 2,3-5,6-8,9-11$

\begin{tabular}{llll}
\hline SLP EXPJAN & & SLP EXPJUL & \\
\hline Year 1 & $\begin{array}{c}\text { Small PPP north of } 50^{\circ} \mathrm{N}, \\
\text { sign. PPP over S. Europe } \\
\text { and NW Pacific }\end{array}$ & Year 1 & $\begin{array}{c}\text { Similar to EXPJAN, higher PPP over } \\
\text { Pacific than in EXPJAN }\end{array}$ \\
Year 2 & Almost no sign. PPP & Year 2 & Almost no sign. PPP \\
$1-2$ month & High PPP in most areas, sign. PPP & $1-2$ month & High PPP in most areas, slightly \\
JF & of NAO and PNA & JA & Sigher than in EXPJAN \\
$3-5$ month & Sign. PPP over N. Pacific & $3-5$ month Pacific \\
MAM & High PPP over N America, & SON & PPP < 0.4 in all areas, PPP \\
$6-8$ month & S. Europe, SW Asia & $6-8$ month & of NAO and PNA not sign. \\
JJA & Almost no sign. Areas & DJF & Almost no sign. Areas \\
$9-11$ month & & $9-11$ month & MAM \\
SON & & &
\end{tabular}

Fig. 4 Top: potential annual mean $2 \mathrm{~m}$ air temperature in the first 2 years after start of the simulations in January (left) and July (right). Bottom: gain of predictability in comparison to the predictability from persistence prognostic predictability of

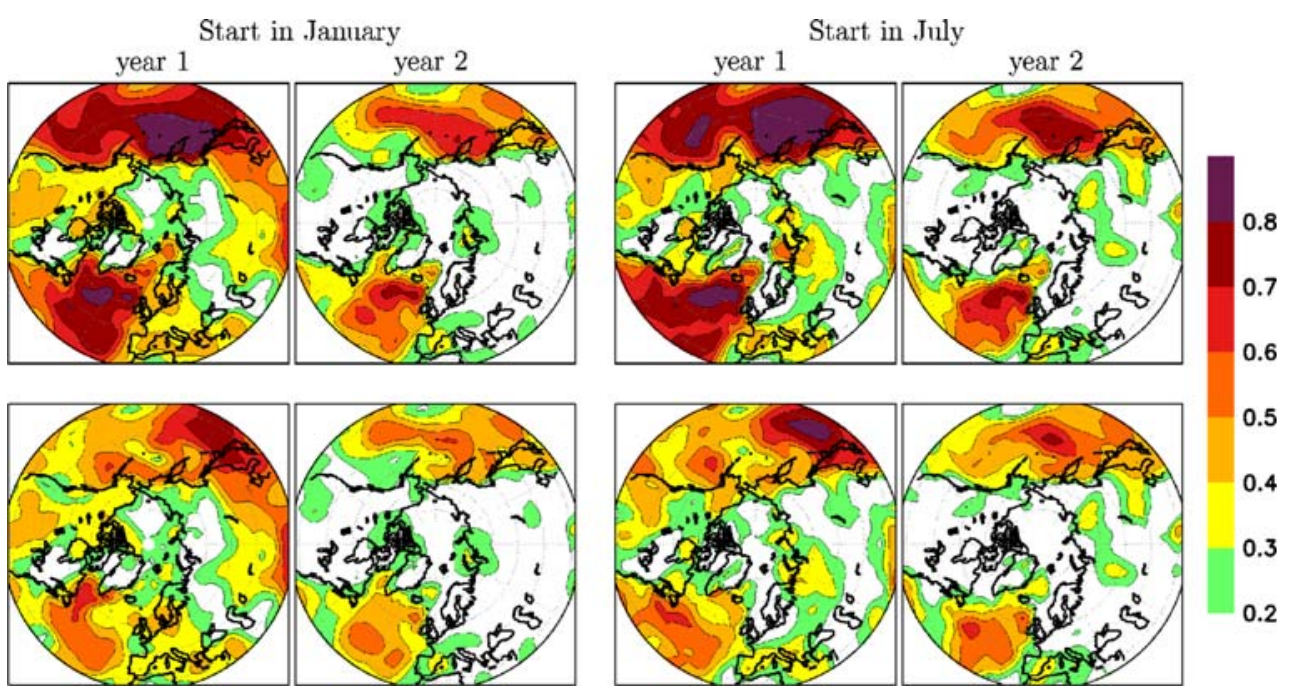

southwest of the Kamchatka Peninsula. Ocean surface temperature itself is highly predictable in these regions (Fig. 5) for several years. The Iceland Basin is rather far away from all continents and SST is spatially uniformly. Hence, atmospheric circulation has only a small impact on $2 \mathrm{~m}$ air temperature. Results by Pohlmann et al. (2004) with a former version of our model showed a high decadal predictability of surface air temperature in this region. Also Boer (2004) showed that decadal potential predictability of surface air temperature is found predominantly over the high latitude oceans.

Our simulations show the largest gain of skill in the northwestern parts of both the North Atlantic and North Pacific (Fig. 4, bottom). In areas dominated by westerlies, persistence is larger over the eastern parts of the oceans than over the western parts because air masses are advected over the oceans and air temperatures are dominated by SST. Advection of air masses from the continents is more

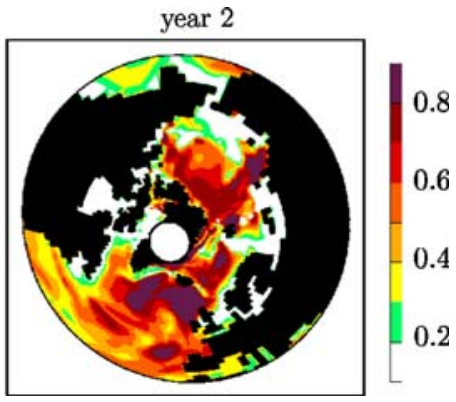

Fig. 5 Potential prognostic predictability of annual mean $6 \mathrm{~m}$ ocean temperature in the first 2 years after start of the simulations in January

important for the western ocean parts. Persistence of air temperature becomes much smaller in the eastern parts after 2 years as well, particularly over the North Atlantic. Hence, dynamic processes must contribute to the high predictability. A lag correlation analysis of $2 \mathrm{~m}$ air temperature over the North Atlantic (averaged over 42-62N,

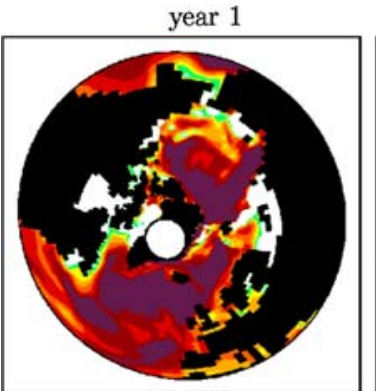


Fig. 6 Top: lag correlation between annual mean $6 \mathrm{~m}$ ocean temperature at the North American east coast and $6 \mathrm{~m}$ ocean temperature in the 300 year control integration. Temperature at the American east coast leads by 1,2 and 4 years. Bottom: same for $6 \mathrm{~m}$ ocean temperature in the Labrador Sea. Temperature in the Labrador Sea leads by 1, 2 and 3 years

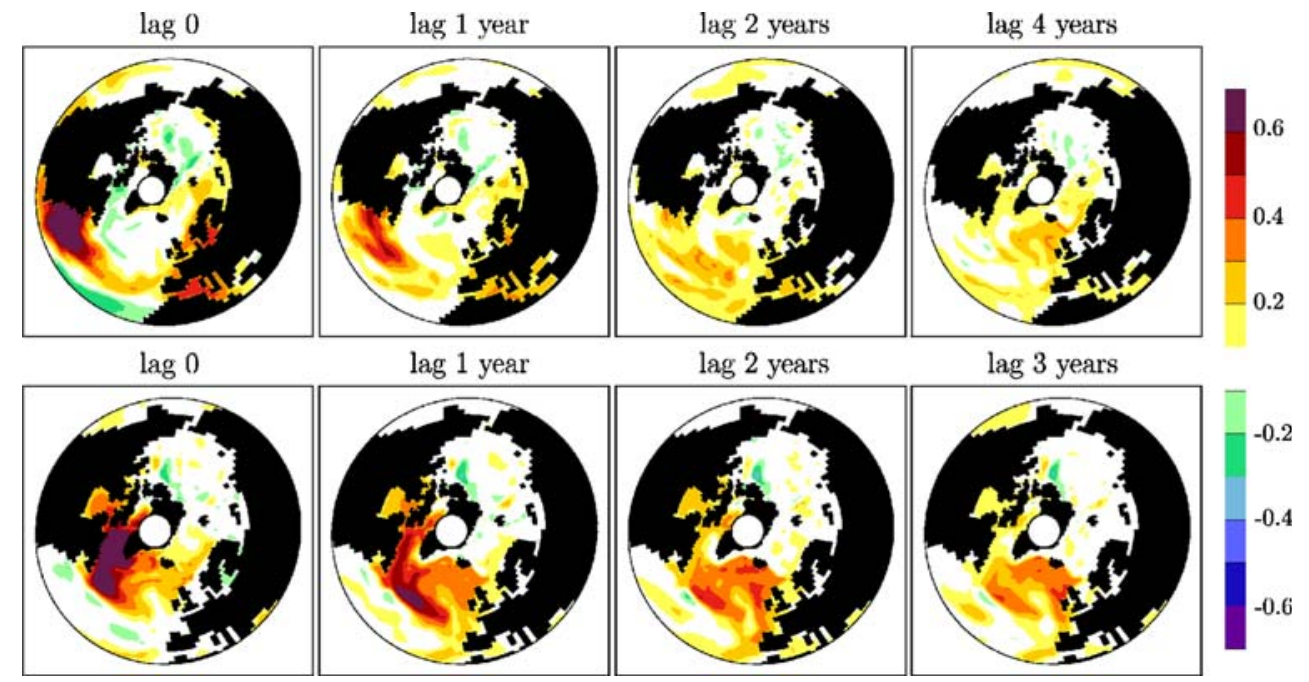

15-45W, Fig. 6) and gridded SST in the 300-year control integration shows that SST anomalies are advected in the North Atlantic Current into the Iceland Basin and in the sub-polar gyre from the Labrador Sea. Advection times are 2-3 years from the Labrador Sea and 4-5 years from the east coast of North America. These advection processes are well documented in literature (Dickson et al. 1988; Ellett and Blindheim 1992). It is more difficult to explain the gain of predictability in the North Pacific. Lag regressions do not show strong advections of upper ocean temperature into this region. However, correlation analyses of the control run suggest that sea ice anomalies in the northern North Pacific may play a role. Furthermore, interannual variations of the atmospheric circulation are partly predictable in this area (Fig. 2) and may explain a part of the predictability.

The predictabilities in EXPJAN and EXPJUL are similar in most ocean regions except for the Labrador Sea. PPP of first-year $2 \mathrm{~m}$ air temperature in the Labrador Sea is very high in EXPJAN and the gain of predictability is the largest in the entire Atlantic Ocean. In contrast, PPP in the Labrador Sea is rather small in EXPJUL. In both experiments, PPP of year 1 is significant in most of western North America and in southern Europe in both experiments. Additionally, EXPJAN shows a positive skill over Northern Europe and over Asia, south of $50^{\circ} \mathrm{N}$ while EXPJUL shows significant values in western Siberia. Predictability of air temperature is small over the Arctic Ocean although PPP of Arctic SST is very large (Fig. 5). In the central Arctic, sea ice cover is high year-round and strongly isolates the atmosphere from the ocean. Hence, air temperature is governed by the atmospheric circulation and the connection to SST is weak. Some areas at the ice edge as, e.g. the Barents Sea or near the coast have a significant PPP since the amount of sea ice plays an important role for air temperature. The second-year PPP is very small over almost all land regions of mid and high northern latitudes and over the Arctic Ocean. Only over southwestern Europe and very few regions of Siberia, predictability reaches up to 0.3 in both experiments.

Analyses of temperature predictability at 850 and $500 \mathrm{hPa}$ height (not shown) indicate a vertical extension of $2 \mathrm{~m}$ air temperature predictability over the North Atlantic and North Pacific up to $850 \mathrm{hPa}$. However, we do not find any significant predictability at $500 \mathrm{hPa}$ height in these regions. The high PPP is limited to the lower troposphere because of the declining impact of the SST with height. Other regions with significant $2 \mathrm{~m}$ air temperature predictability like southern Europe or Alaska show also significant predictability at $500 \mathrm{hPa}$ height. Atmospheric dynamics are responsible for this predictability. The largest $500 \mathrm{hPa}$ predictability occurs southwest of Spain, in the southeastern Mediterranean and west of the United States.

Figure 7 shows the seasonal predictability of $2 \mathrm{~m}$ air temperature in EXPJAN and EXPJUL. In EXPJAN, air temperature is highly predictable in most regions of mid and high northern latitudes in the first 2 months after start of the ensemble simulations. PPP exceeds 0.8 over the northern North Atlantic and in some regions of the North Pacific. This is related to a relatively small predictability of SLP in this region. PPP over Europe and North America reaches generally $0.5-0.7$. As the persistence of continental air temperature is very low, the gain of predictability is similar to the PPP-values. Over most ocean regions, the gain varies between 0.3 and 0.5 (not shown). A very interesting region is the Barents Sea where predictability is very high and largely exceeds the predictability of the surrounding areas. Air temperature in the Barents Sea is strongly determined by sea ice concentration, which has a high persistence for several months. Hence, the gain of predictability is small (not shown). In the Barents Sea, our model overestimates ice cover, which might have an 
Fig. 7 Top: potential prognostic predictability of seasonal mean $2 \mathrm{~m}$ air temperature for months $1 / 2$, $3-5,6-8$ and $9-11$ after start of the simulations in January. Bottom: same for initialization in July

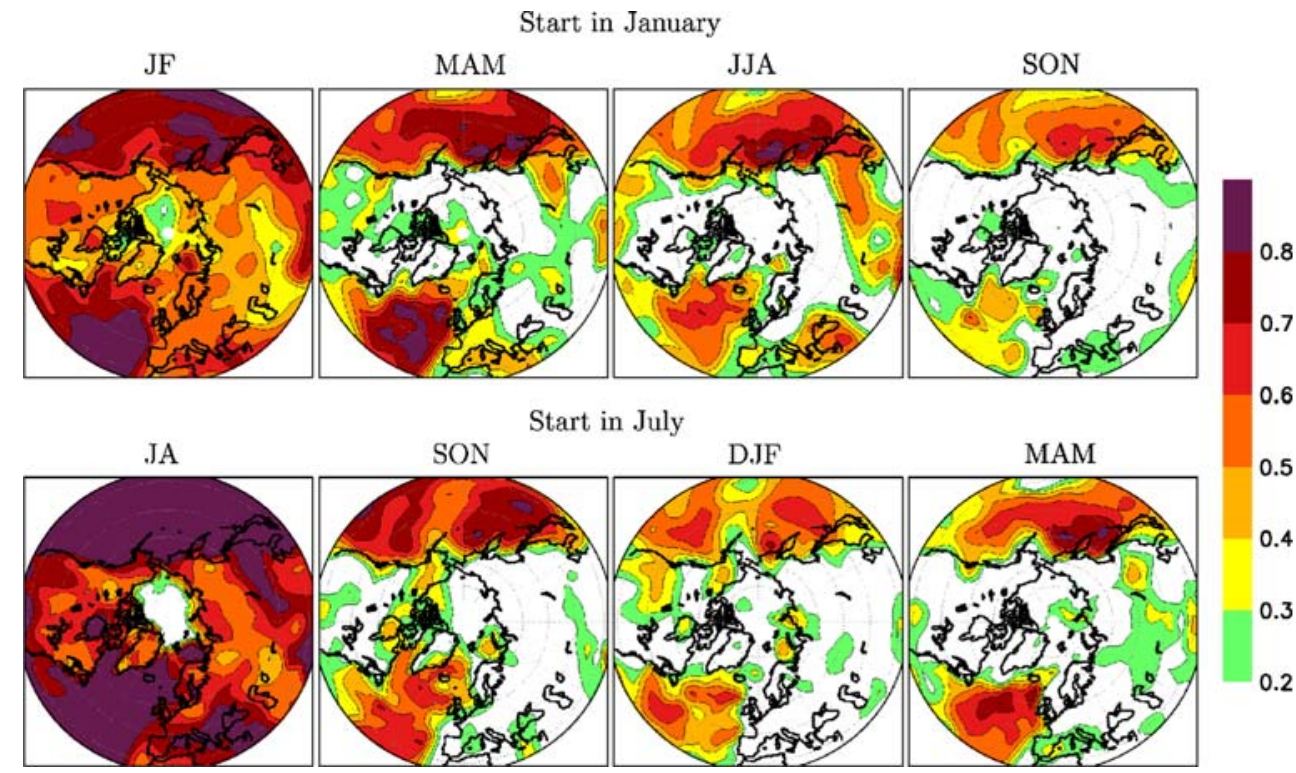

impact on the predictability. Most likely this leads to a shift of the high predictabilities in the Barents Sea with the ice edge to the southwest compared to real world conditions. The 3-5 month PPP of $2 \mathrm{~m}$ air temperature is dominated by a strong land-sea contrast with high PPP over the oceans and small PPP over the continents. Nevertheless, PPP is still significant in most European regions, in parts of Northern America and in southeastern Russia/northeastern China. This predictability is mainly due to dynamical features and cannot be obtained by persistence. In summer (mean of 6-8 months, JJA) predictability stays high over the oceans but is close to zero in all Arctic regions. A high potential predictability occurs over southeastern Europe and still over southeastern Russia/northeastern China. As discussed above, ENSO is responsible for these high predictabilities in our model. Colman and Davey (1999) used January-February SST anomalies in the North Atlantic to predict the following summer air temperature over Europe. They found significant forecast skills in large parts of western Europe. Barnston and Smith (1996) showed a significant skill of summer air temperature over southern Europe, the US including parts of Alaska and over a small area near Lake Baikal. This agrees with our results of summer air temperature over Europe and North America but our results show a much larger region with significant skill over southeastern Russia/northeastern China.

Predictability in our EXPJAN simulations is strongly reduced in the autumn season (mean of 9-11 months, SON). Even over the North Atlantic and North Pacific, PPP decreases due to strong winds, which lead to a higher dependency of air temperature on the atmospheric circulation.

The seasonal predictabilities of air temperature in EXPJUL and EXPJAN differ. In EXPJUL, PPP is larger in almost all areas of mid and high northern latitudes except for the Arctic Ocean in the first 2 months. The impact of ENSO explains higher PPP-values over land regions in EXPJUL. The spatial predictability distribution is similar to the summer pattern in EXPJAN but values are larger in EXPJUL due to shorter lead time. The persistence over the oceans is especially large in summer due to weak winds, and leads to almost perfect predictability. The 3-5 month predictability is smaller in EXPJUL than in EXPJAN. In months $6-8$, there is still some predictability of temperature over western North America. Some parts of Asia show significant predictability in the following spring (months 9-11). PPP over the North Atlantic and North Pacific remains high in these seasons. The predictability pattern of year-1 is obviously related to the seasonal predictability. For example, the significant predictability in EXPJAN over Europe in the first year is mainly due to high predictabilities in the first two seasons. The summer predictability strongly contributes to the year-1 predictability over southeastern Europe and southeastern Russia/northeastern China. There are no regions with significant annual predictability, which do not show significant seasonal predictabilities.

Main results from the analysis of seasonal to interannual potential predictability of $2 \mathrm{~m}$ air temperature are summarized in Table 2.

The predictability of area means may lead to different predictabilities than the average of the grid point predictability in the same region. Thus, Figs. 8 and 9 show the seasonal predictability of area mean air temperatures for different land regions in mid and high northern latitudes in EXPJAN and EXPJUL. The predictability of air temperature in northern and middle Europe is significant in the first two seasons after initialization in January. In southern 
Table 2 Summary of seasonal to interannual potential predictability of $2 \mathrm{~m}$ air temperature for the annual means of the first two years and the means of the months $1 / 2,3-5,6-8,9-11$

\begin{tabular}{|c|c|c|c|}
\hline \multicolumn{2}{|l|}{ T 2 m EXPJAN } & \multicolumn{2}{|c|}{ T 2 m EXPJUL } \\
\hline Year 1 & $\begin{array}{l}\text { High PPP over N. Atlantic and N. Pacific, sign. } \\
\text { but }<0.5 \text { over Europe and N. America }\end{array}$ & Year 1 & $\begin{array}{l}\text { Similar to EXPJAN but smaller } \\
\text { PPP over the continents }\end{array}$ \\
\hline Year 2 & $\begin{array}{l}\text { High PPP over N. Atlantic and N. Pacific, small } \\
\text { over continents and Arctic }\end{array}$ & Year 2 & Similar to EXPJAN \\
\hline $\begin{array}{l}1-2 \text { month } \\
\text { JF }\end{array}$ & High PPP in most areas & $\begin{array}{l}1-2 \text { month } \\
\text { JA }\end{array}$ & $\begin{array}{l}\text { High PPP in most areas, slightly } \\
\text { higher than in EXPJAN }\end{array}$ \\
\hline $\begin{array}{l}3-5 \text { month } \\
\text { MAM }\end{array}$ & $\begin{array}{l}\text { High PPP over ice-free oceans, sign. in Europe } \\
\text { and parts of NW America }\end{array}$ & $\begin{array}{l}3-5 \text { month } \\
\text { SON }\end{array}$ & $\begin{array}{l}\text { High PPP over ice-free oceans, } \\
\text { sign. over Alaska/N. Canada }\end{array}$ \\
\hline $\begin{array}{l}6-8 \text { month } \\
\text { JJA }\end{array}$ & $\begin{array}{l}\text { High PPP over N. Atlantic and N. Pacific, high } \\
\text { over SE Europe, S. Russia/N. China }\end{array}$ & $\begin{array}{l}6-8 \text { month } \\
\text { DJF }\end{array}$ & $\begin{array}{l}\text { High PPP over N. Pacific and N. } \\
\text { Atlantic, sign. over parts of } \\
\text { western N. America }\end{array}$ \\
\hline $\begin{array}{l}9-11 \text { month } \\
\text { SON }\end{array}$ & $\begin{array}{l}\text { High PPP over N. Pacific, sign. over N. Atlantic, } \\
\text { not sign. over continents }\end{array}$ & $\begin{array}{l}\text { 9-11 month } \\
\text { MAM }\end{array}$ & $\begin{array}{l}\text { High PPP over N. Atlantic and N. } \\
\text { Pacific, not sign. over continents }\end{array}$ \\
\hline
\end{tabular}
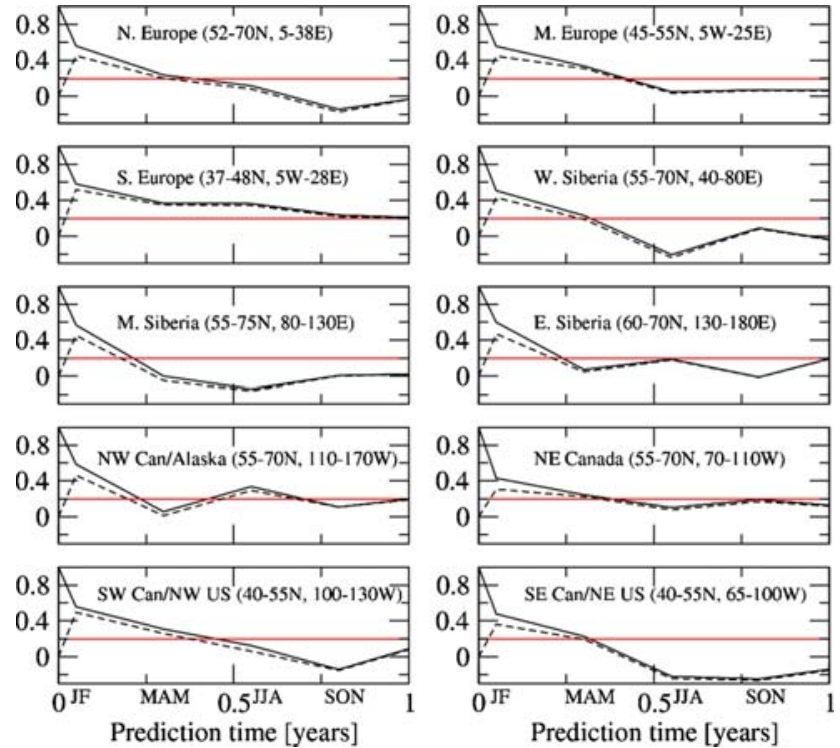

Fig. 8 Potential prognostic predictability of seasonal mean $2 \mathrm{~m}$ air temperature, averaged over different land regions of mid and high northern latitudes, in the first year after start of the simulation in January. The dotted line shows the gain of predictability and the red line the level of $95 \%$ significance

Europe, predictability is larger and significant in the entire first year. This changes if initialization takes place in summer. PPP is already quite small in autumn and below (northern Europe) or near the 95\% significance level (middle and southern Europe). However, predictability increases in northern Europe in the following winter, in middle Europe in the following spring and in southern Europe in spring and summer. Obviously, PPP of air temperature in Europe shows a seasonal cycle. In southern Europe, PPP is largest in summer and in northern Europe largest in winter. The 3-5 month predictability is small in
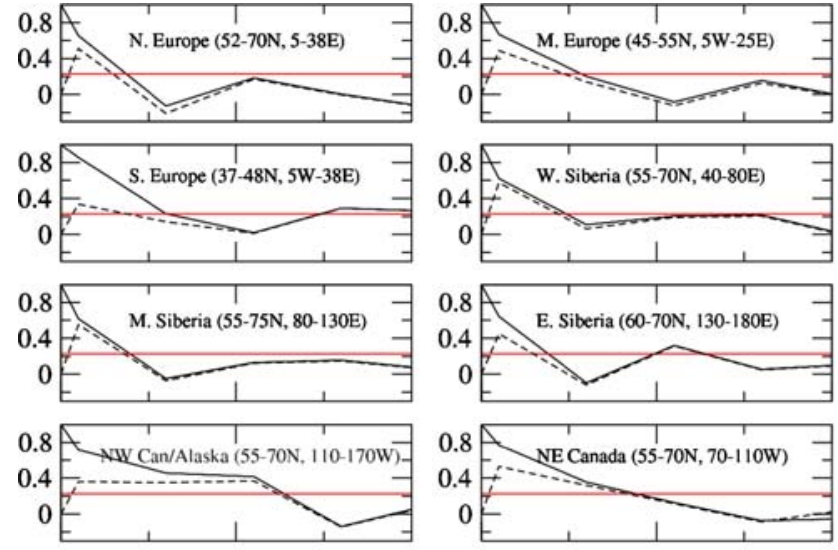

$0.8 \overbrace{\text { sw Can/Nw US }}^{\prime}\left(40.55 \mathrm{~N}, 100-130 \mathrm{w}^{\prime}\right.$

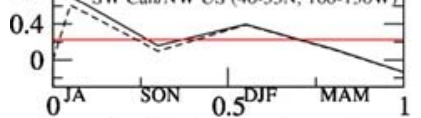

Prediction time [years]
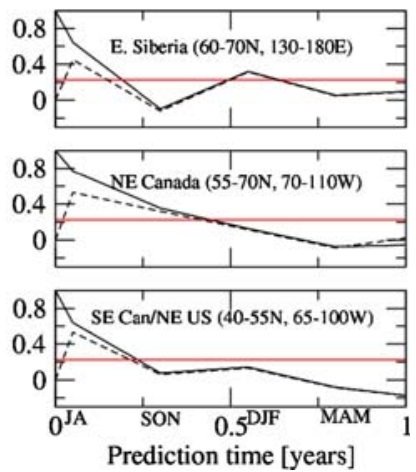

Fig. 9 Same as Fig. 8 but after initialization in July

Siberia and only significant in western Siberia in EXPJAN. In EXPJUL, air temperature shows significant predictive skill in eastern Siberia during winter. Predictability over North America is largest in the southwestern part in EXPJAN and in the northwestern part in EXPJUL. This agrees with findings of Van den Dool et al. (2006) who showed that seasonal predictability over North America is mainly dominated by the Pacific. Barnston and Smith (1996) found lowest predictability over Europe with little skill in late summer and a clear seasonal cycle with moderate forecast skill in summer and winter over North America. This is similar to our findings, although not directly comparable because they averaged temperature over the entire continents. 
The predictability of $2 \mathrm{~m}$ air temperature averaged over four different ocean regions is shown in Fig. 10. Predictability over the northern North Atlantic and the northern North Pacific is very high for several years and has a marked seasonal cycle. PPP is much larger in spring and summer than in autumn and winter. Both experiments show this seasonality. Main reason is a stronger wind in autumn and winter, which leads to a larger impact of the highly varying atmospheric circulation on $2 \mathrm{~m}$ air temperature. Particularly in the Pacific, this is connected with a much higher persistence during spring and summer. The gain of predictability does not show a marked seasonality over the North Pacific and the seasonal amplitude is slightly reduced over the North Atlantic compared to the predictability itself. Our results agree with findings of Collins (2002), who analyzed SST predictability of the first 5 years mean with perfect model experiments. He also found a very high predictability of SST in the North Atlantic. The predictability shows a seasonal cycle with a maximum in spring and summer but with slightly reduced amplitude compared to our simulations. This may be due to the fact that he used SST while we used $2 \mathrm{~m}$ air temperature, which is more affected by winds. In our control integration, decadal to multidecadal variations of $2 \mathrm{~m}$ air temperature in the North Atlantic and the North Pacific are of about the same size as interannual variations and contribute to the high predictability. Air temperature in the Labrador Sea is

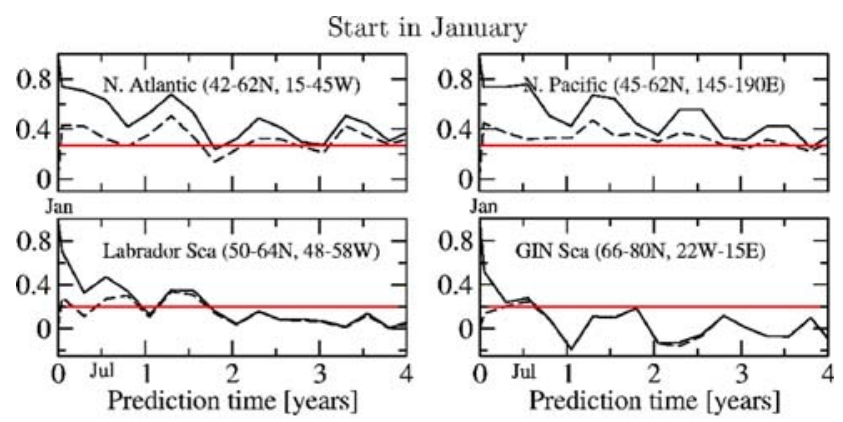

Start in July
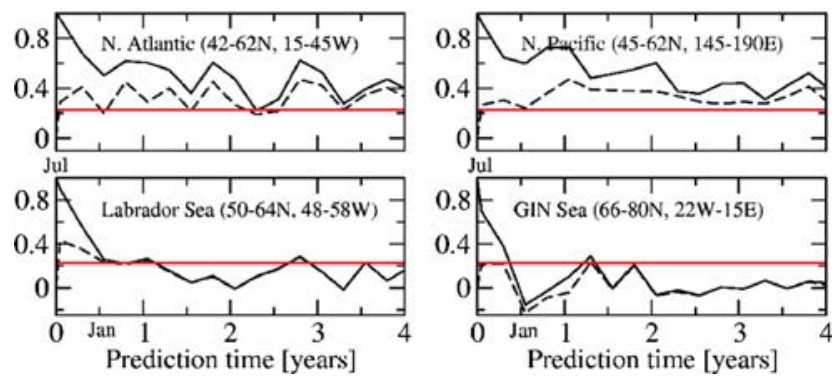

Fig. 10 Potential prognostic predictability of seasonal mean $2 \mathrm{~m}$ air temperature, averaged over different ocean regions of mid and high northern latitudes, in the first 4 years after start of the simulations in January (top) and July (bottom). The dotted line shows the gain of predictability and the red line the level of $95 \%$ significance significantly predictable for about one and a half years and 1 year in EXPJAN and EXPJUL, respectively. The gain of predictability is very high in the Labrador Sea. Koenigk et al. (2006) showed that sea ice exports through Fram Strait have a significant impact on air temperature in the Labrador Sea. However, the general predictability analyzed in this study seems to be smaller than temperature predictability after large Fram Strait sea ice export anomalies as analyzed by Koenigk et al. (2006). A strong oceanic signal is necessary to overcome atmospheric noise and to obtain a large impact on air temperature in the Labrador Sea.

The potential predictability of precipitation is relatively small (not shown) and is mainly dominated by the atmospheric circulation. Where SLP is significantly predictable, precipitation reaches similar PPP-values to those of SLP. Air temperature and SST seem to have only limited impact on precipitation. At least, we do not find enhanced predictability of precipitation over the North Atlantic and North Pacific, where temperature is highly predictable for several years.

\subsection{Predictability of sea ice and ocean variables}

Sea ice cover and sea ice thickness control most of the fluxes of heat, matter and momentum between ocean and atmosphere. The variations of these fluxes are particularly large at the ice edge and are important for local and maybe also for large-scale climate conditions. A number of studies show an impact of sea ice anomalies on the atmospheric circulation (Deser et al. 2004; Magnusdottir et al. 2004; Alexander et al. 2004; Kvamstö et al. 2004; Koenigk et al. 2006) or use sea ice as boundary forcing for predictability studies. In spite of its large relevance for climate, the predictability of sea ice is poorly analyzed so far. Figure 11 shows a high potential predictability of annual mean sea ice thickness in almost the entire Arctic Ocean in the first 2 years. PPP in the Labrador Sea, Hudson Bay and Bering Sea is much larger in EXPJAN than in EXPJUL. Main reason is that no or only little ice exists in these regions during summer. Hence, ice thickness in the first year depends on ice formation during the following winter, which is strongly affected by quite unpredictable atmospheric parameters. PPP is slightly higher in EXPJUL than in EXPJAN in the northern Barents Sea and the Kara Sea. However, PPP is near zero in the second year in both experiments. In the Arctic Ocean, persistence of sea ice thickness dominates the predictability. A considerable gain of predictability compared to persistence occurs in parts of the transpolar drift stream (TDS), in the East Greenland Current (EGC) and particularly in the Labrador Sea. This is related to a sea ice/climate mode, which is characterized by formations of sea ice thickness anomalies at the Siberian 
Fig. 11 Top: potential prognostic predictability of annual mean sea ice thickness in the first 2 years after start of the simulations in January (left) and July (right). Bottom: gain of predictability in comparison to the predictability from persistence
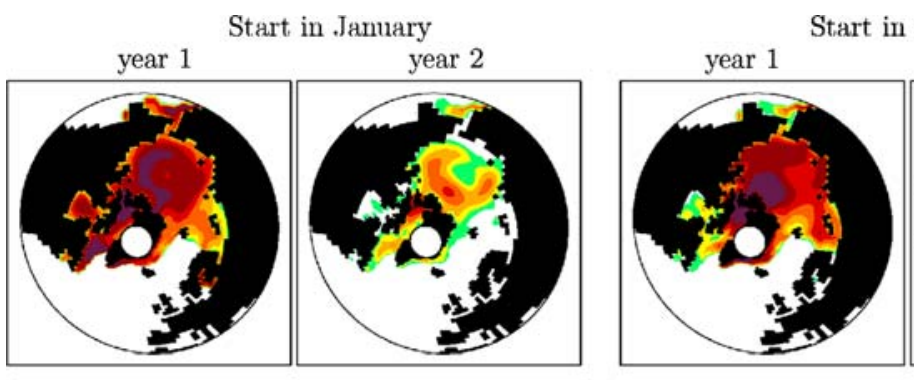

Start in July

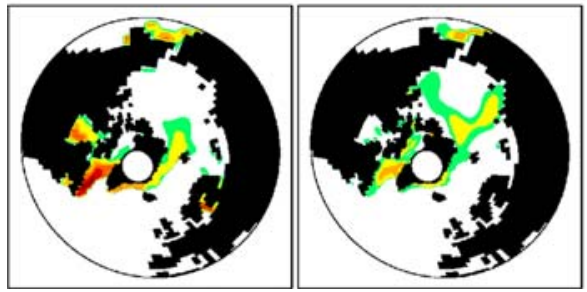

coast, propagation in the TDS, anomalous Fram Strait sea ice export and subsequent propagation of the sea ice/ freshwater anomaly to the Labrador Sea (Koenigk et al. 2006). Convection in the Labrador Sea is affected and consequently SST and sea ice distribution in the Labrador Sea. The advection of the anomaly in the EGC towards Labrador Sea is rather independent of the atmospheric circulation and leads to a large gain of predictability. Sea ice transports in the EGC have a high predictability in the first year (not shown). Elsewhere, PPP of sea ice transports is rather small because they are governed by the atmospheric circulation with low predictability in most Arctic regions.

The predictability of annual mean sea ice concentration in the first year is very small in the entire Arctic Basin in EXPJAN and in the interior of the central Arctic in EXPJUL (Fig. 12). Obviously, PPP is small where sea ice concentration is near one at the initialization time. In these regions, it is independent from oceanic and atmospheric initial conditions. This means that the variance of sea ice concentration in the ensembles is of about the same size than that in the control integration. Hence, predictability is very small. High predictabilities occur along the ice edges, in regions with reduced concentration and additionally along the coasts of the Arctic Basin in EXPJUL. The persistence of sea ice concentration is rather small in EXPJAN but explains most of the first-year predictability in EXPJUL. The reason is that ice concentration anomalies are large in summer and persist until next winter while ice concentration anomalies are small in winter because concentration is almost everywhere near one. Hence, persistence is low for a lag of more than 1 year in both experiments. The predictability distribution of sea ice reflects well the variance of sea ice concentration. The variance is the largest at the ice edge, particularly in the
Barents Sea and is very small in the central Arctic. Grumbine (1994) suggested that predictability of sea ice cover is particularly long-lasting in areas where growth and decay rates are only partly dependent on ice thickness. This is the case during summer and year-round for thick sea ice. Our results agree only partly with Grumbine's because we found a small predictability of sea ice cover in areas with thick ice. However, our simulations show a large predictability of sea ice thickness in these areas.

The seasonal predictability of sea ice thickness and concentration averaged over certain Arctic regions after initialization in January is shown in Fig. 13. In the central Arctic and in the Laptev/East Siberian Seas, sea ice thickness is highly predictable mainly due to persistence. In contrast, sea ice concentration shows very small predictability. Sea ice thickness and concentration are not significantly correlated in these regions. This is different along the ice edge, where predictabilities of sea ice thickness and concentration are about the same. PPP in the Barents/Kara Seas and Greenland/Iceland Seas is significant for 6 months to 1 year. Predictability of Barents/Kara Seas ice lasts somewhat longer in EXPJUL than in EXPJAN and vice versa in the Greenland/Iceland Seas (not shown). Both experiments show smallest predictability of sea ice in Barents/Kara Seas in autumn. Particularly in the Barents Sea, persistence is rather high in the first year and explains a large part of the predictability. Predictability of Labrador Sea ice conditions is significant for about 2 years and it is slightly larger in EXPJAN than in EXPJUL. The gain of predictability is rather large in the Labrador Sea in comparison to the other regions. Persistence dominates the first months but thereafter dynamic processes govern the predictability.

Figure 14 shows the potential predictability of annual mean surface salinity in the first 2 years after initialization. 
Fig. 12 Top: potential prognostic predictability of annual mean sea ice concentration in the first 2 years after start of the simulations in January (left) and July (right). Bottom: gain of predictability in comparison to the predictability from persistence
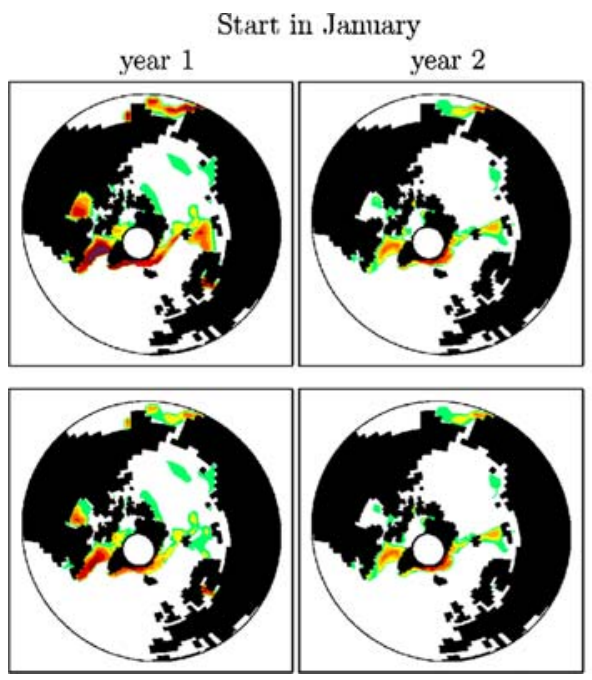

Start in July

year $1 \quad$ year 2
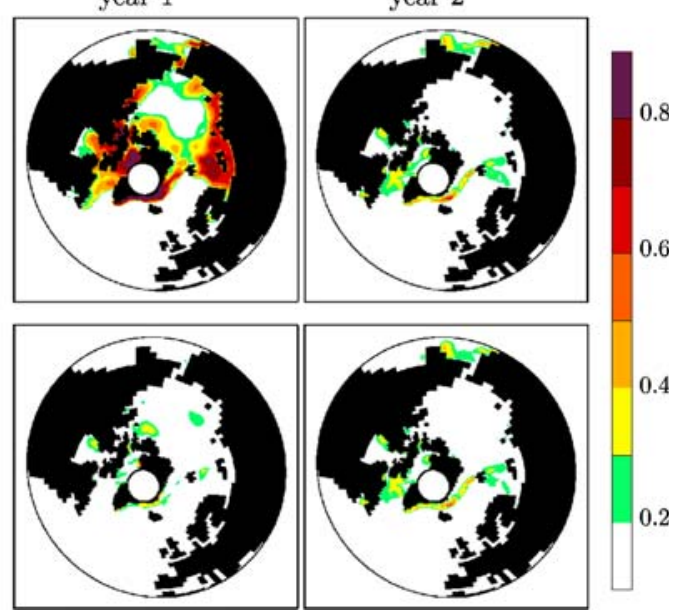
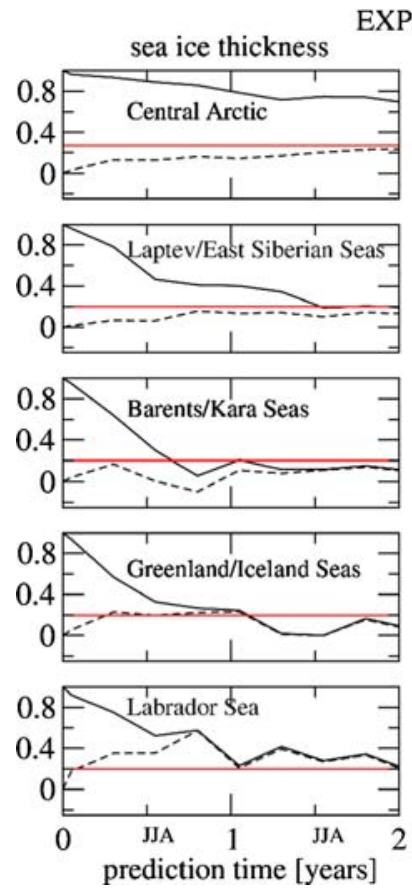

sea ice concentration
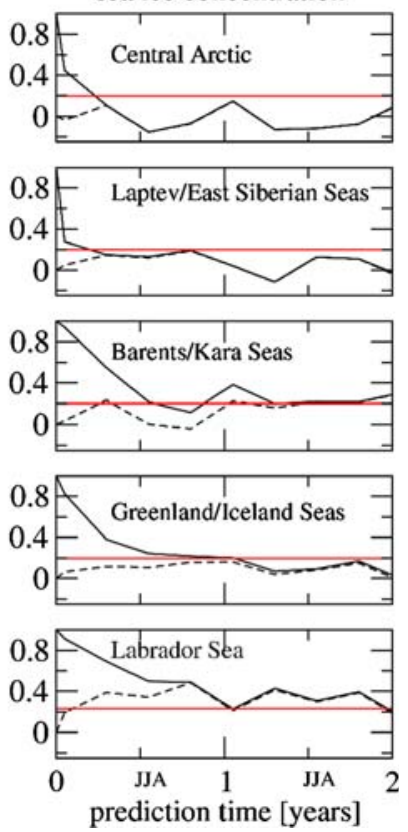

Fig. 13 Potential prognostic predictability of seasonal mean sea ice thickness and concentration, averaged over different Arctic regions, in the first 2 years after start of the simulation in January. The dotted line shows the gain of predictability and the red line the level of $95 \%$ significance

PPP exceeds 0.8 in most areas in year 1 . River runoff and ice melting/ freezing lead to smaller predictability in some coastal areas and regions near the ice edge. The gain of predictability in the first year relative to persistence is particularly large in the North Atlantic Drift, in the Labrador Sea and the Nordic Seas. Main reason is advection of water masses in the North Atlantic Drift and the sub-polar gyres. As already discussed, sea ice exports from the Arctic through Fram Strait strongly influence upper ocean salinity

in the Labrador Sea (Haak et al. 2003; Häkkinen 1999; Dickson et al. 1988). The high predictability in the Arctic Ocean is mainly due to high persistence. With increasing lead time, areas with low potential predictability extend from coastal regions and ice edges into the ocean interiors. However, predictability of surface salinity remains high in the central Arctic and in the northeastern North Atlantic and North Sea for several years (not shown). The patterns of predictability gain become similar to the PPP-patterns because the persistence is relatively small in most regions after 2 years. The results from EXPJUL and EXPJAN agree very well for PPP but differ for the gain of PPP in the first year. Persistence in the North Atlantic is larger after start in July than in January. Griffies and Bryan (1997) used a global coupled model and showed that EOF-1 of surface salinity in the North Atlantic is predictable for about one decade. The EOF-1 pattern is dominated by a dipole with centers in the middle of the North Atlantic south of Iceland and Greenland and along the northeastern United States extending towards Labrador Sea. In the area of the eastern pole, our model simulations show long-lasting predictabilities as well while predictability at the northeastern coast of the United States is limited in our model.

The freshwater content of the upper 100, 200 and $500 \mathrm{~m}$ has been analyzed (not shown). The patterns are very similar to the one of surface salinity. However, the PPP slightly increases with increasing deeper integration limit.

The predictability of seasonal mean surface salinity averaged over the same ocean regions as for air temperature is shown in Fig. 15. Predictability is very good for several years in the North Atlantic. In contrast to air temperature, PPP of salinity does not show any seasonality in EXPJAN and only a slight tendency to higher PPP during winter in EXPJUL. Surface salinity does not depend on the atmospheric circulation but responds on much longer timescales in the northern North Atlantic. Hence, PPP of 
Fig. 14 Top: potential prognostic predictability of annual mean salinity in the first 2 years after start of the simulations in January (left) and July (right). Bottom: gain of predictability in comparison to the predictability from persistence
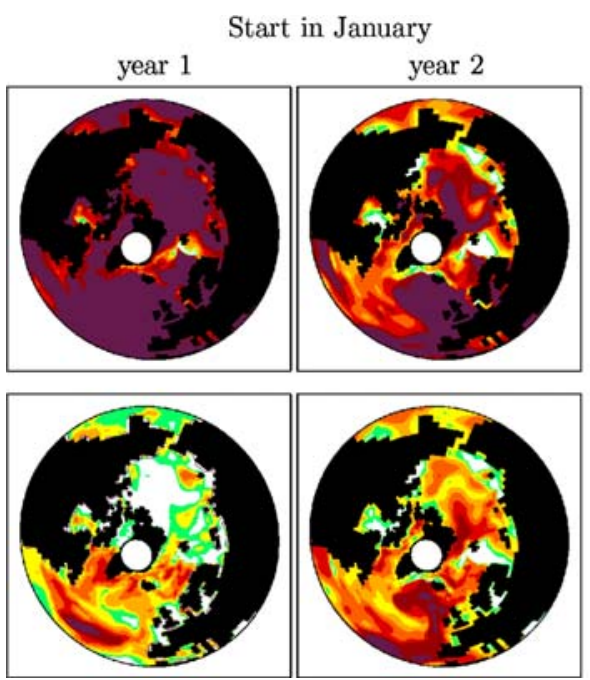

Start in July
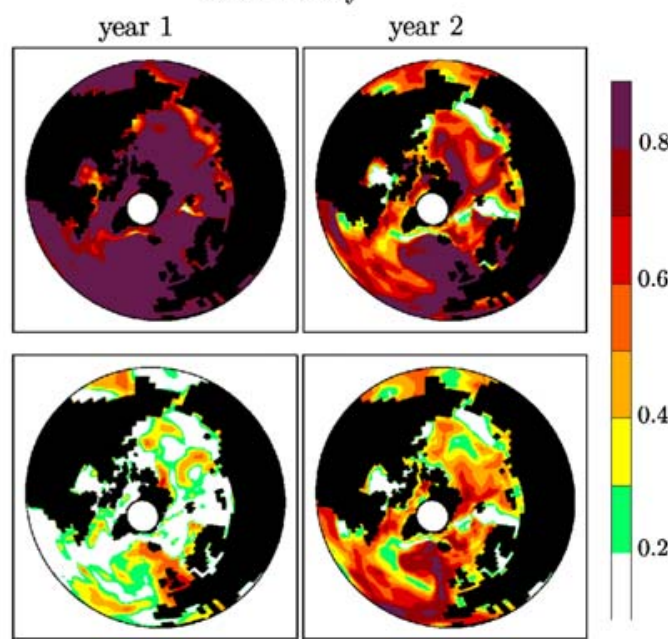

salinity is not decreased in autumn and winter. Persistence accounts for a large part of the predictability in the first seasons but decreases to about one third after 2 years. PPP of salinity shows similar high values in the North Pacific in the first year due to high persistence but drops faster to smaller values than in the North Atlantic. Persistence explains about $50-70 \%$ of the seasonal predictability in the second and third year but decreases thereafter. Surface salinity in the Labrador Sea shows a rather high predictability with lead times up to 2 years. The persistence is
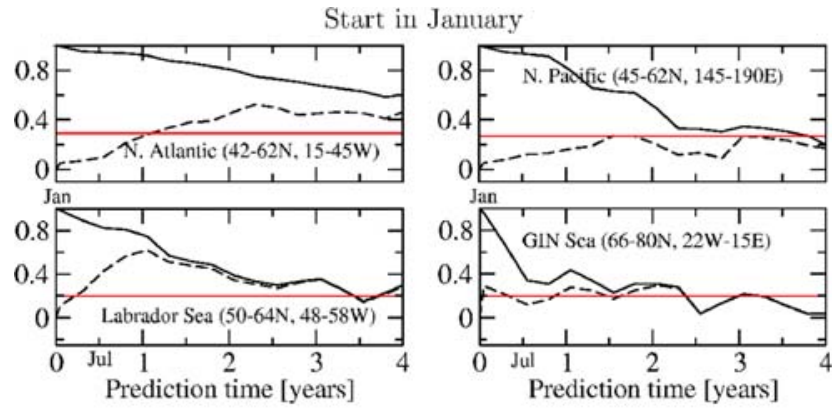

Start in July
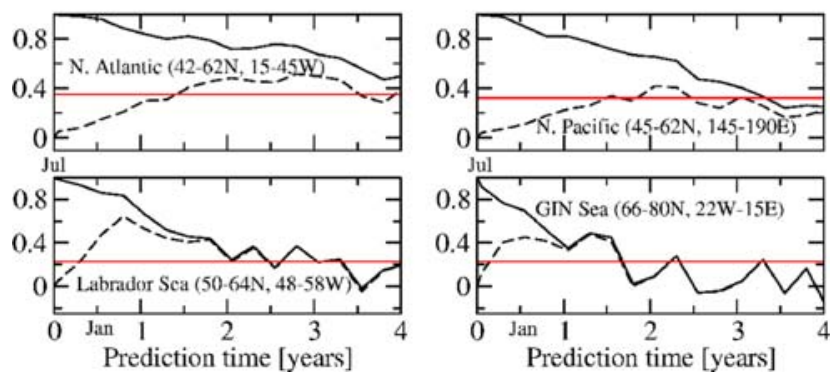

Fig. 15 Potential prognostic predictability of seasonal mean $6 \mathrm{~m}$ salinity, averaged over different ocean regions of mid and high northern latitudes, in the first 4 years after start of the simulations in January (top) and July (bottom). The dotted line shows the gain of predictability and the red line the level of $95 \%$ significance much weaker than in the North Atlantic and North Pacific and hence, PPPa is very high. The mechanisms leading to the large gain of predictability has been discussed in detail above. PPP in the Greenland Sea is significant for about one and a half years. The predictability shows a seasonal cycle with maximum in winter and minimum in summer.

Figure 16 analyzes the predictability of integrated oceanic time series. PPP of sea ice export through Fram Strait is small but significant in the first 2 years. Advection of sea ice thickness anomalies from the Siberian coast to the Fram Strait in the TDS is responsible for the predictability as has been shown by Koenigk et al. (2006). Predictability of both Denmark Strait overflow and MOC is very high and significant for many years. However, persistence is much more dominating in the overflow than in the MOC. Spectral analyses show that decadal to multidecadal variations are
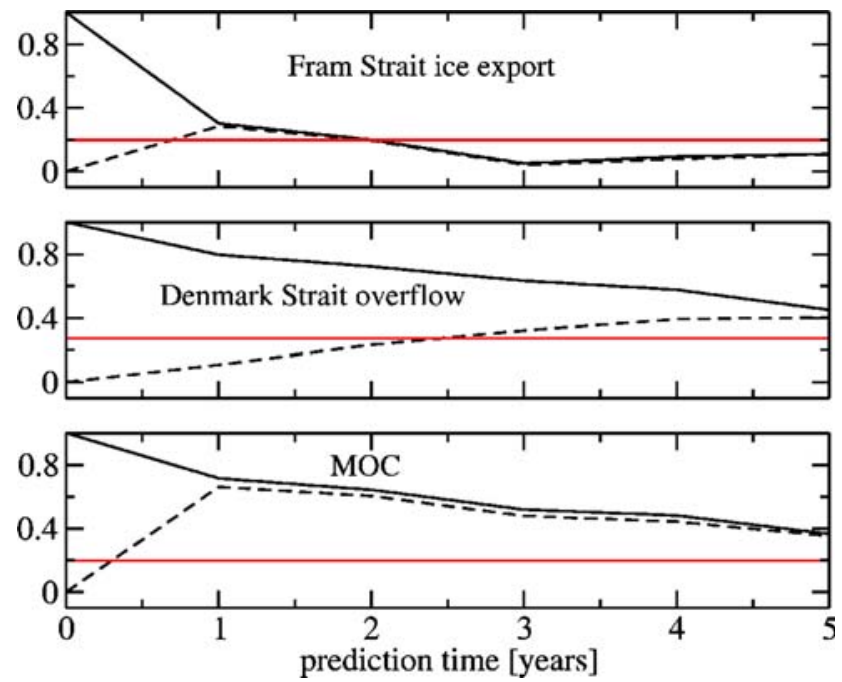

Fig. 16 Potential prognostic predictability of annual mean Fram Strait sea ice export, Denmark Strait overflow and MOC at about $30^{\circ} \mathrm{N}$ after initialization in January 
more pronounced in the Denmark Strait overflow than in the MOC. Furthermore, the high-frequency part of the MOC ( $f<10$ years) is at least partly wind-driven (Kanzow et al. 2007; Hirschi and Marotzke 2007). Collins et al. (2006) analyzed interannual to decadal predictability of the MOC in five different AOGCM and found similar to us high skill for at least 5-10 years.

\section{Summary and conclusions}

The potential predictability of seasonal to interannual climate in mid and high northern latitudes has been analyzed with a perfect model approach. Two sets of ensemble experiments initialized in January and July have been performed with the AOGCM ECHAM5/MPI-OM.

The potential predictability of the atmospheric circulation is rather small. However, some significant predictability has been found for annual mean SLP over southeastern Europe, northwestern Pacific and Canada. Predictability is generally smaller in the high latitudes than further south except for northern Canada. Seasonal climate predictability seems to be promising over the northwestern North Pacific up to half a year in advance and over North America and southern Europe in the summer season. Predictability of precipitation is rather low because it is mainly governed by the atmospheric circulation.

The predictability of $2 \mathrm{~m}$ air temperature is characterized by a strong land-sea contrast. Over the continents, predictability of annual mean air temperature is limited to the first year. Significant seasonal predictability is obtained over southern Europe and western NortSh America up to half a year in advance. Furthermore, the seasonal predictability over continents except for northern North America is larger after initialization in winter than in summer. This is mainly due to the fact that predictability in autumn is smallest and hence the 3rd-5th month predictability is smaller after start in July than in January. In contrast to the continents, predictability over the oceans, particular over the North Atlantic and North Pacific, is very high for several years in advance. Here, air temperature is strongly connected with the ocean surface temperature. Advection of SST anomalies in the sub polar gyre and the North Atlantic Drift leads to a strong gain of predictability in the North Atlantic Ocean compared to the predictability from persistence. The predictability over the oceans shows a strong seasonal cycle with higher predictability in summer than in winter. Winds are weaker and hence the impact of the highly variable atmospheric circulation on $2 \mathrm{~m}$ air temperature is smaller in summer than in winter. Concerning predictability of air temperature, one may argue that predictability in inhabited regions is of more interest than in uninhabited regions. Moreover, predictability in regions with high temperature variability is more important than in low-variability-regions. From this point of view, the high predictability of air temperature in the northern North Atlantic Ocean is rather useless as no one lives there and even seasonal standard deviations do not exceed $0.5 \mathrm{~K}$, which is among the smallest of the entire mid and high latitudes. However, the existence of high predictability indicates relevant physical processes in that area. The analysis of these processes in order to understand the found predictability deepens the understanding of physical mechanisms and processes in the climate system. This might also be important for forecasts in inhabited regions as well.

Annual mean sea ice thickness in the Arctic Basin is highly predictable in the first 2 years mainly due to persistence. In the Labrador Sea and the East Greenland Current, predictability of sea ice thickness is high due to advection of sea ice from Fram Strait. Some gain of predictability could also be found in the Transpolar Drift Stream due to advection of sea ice from the Siberian coast across the North Pole towards Fram Strait. In contrast to sea ice thickness sea ice cover has a low predictability in the central Arctic but shows some skill along the ice edges and the coasts. Predictability is larger after initialization in summer than in winter except for the Labrador Sea. We think the main reason is that differences in sea ice concentration in different years are much smaller in winter than in summer. Sea ice concentration is near one in almost the entire Arctic Ocean in winter independent of the year, while summer-to-summer variations are much stronger.

Surface salinity in the Arctic Ocean also shows a high predictability. Similar to sea ice thickness, this is mainly due to large persistence in the central Arctic while persistence is highly exceeded in the East Greenland Current and the Labrador Sea. Very high and long-lasting predictabilities of salinity occur in the North Atlantic. The reason for this is similar than for air temperature in the North Atlantic. However, PPP of salinity does not show any seasonal cycle in the North Atlantic. Salinity in the North Pacific is predictable for about 4 years and shows a slight tendency to higher predictabilities during summer and autumn than during winter and spring. MOC and Denmark Strait overflow are highly predictable for 5 or more years.

The analyses of seasonal predictability show that the forecast skill depends on the target-season and partly on the time of initialization. The importance of the target-season for the predictive skill seems to be most pronounced for atmospheric parameters but plays a small role in ocean and sea ice as well.

Again, it has to be pointed out that we analyzed perfect model ensembles. That means initial conditions are perfect except for a marginal perturbation. In reality such good initial conditions will probably never be reached. 
Moreover, the concept of perfect model predictability studies does not take into account existing model errors, which in the real world will always lead to reduced forecast skill. Under the assumption that our model realistically represents real climate, one will never be able to predict a certain climate variable in regions with no or very small predictability. A high predictability does not mean that a forecast is possible in reality but there is clear chance for climate forecasts in future. Hence, future predictability studies have to focus on finding suitable initialization methods for coupled models. In the Arctic, the initialization of sea ice thickness and concentration is particularly important for climate forecasts. Since sea ice distribution is strongly dependent on the atmospheric circulation it may be possible to obtain rather realistically initial sea ice conditions in the model with the aid of windstress reanalysis data. The initialization of sea ice may be further simplified by launching CryoSat in 2009 .

Acknowledgments This work was supported by the Deutsche Forschungsgemeinschaft through the Sonderforschungsbereich 512. The computations have been performed by the Deutsches Klima Rechenzentrum (DKRZ).

Open Access This article is distributed under the terms of the Creative Commons Attribution Noncommercial License which permits any noncommercial use, distribution, and reproduction in any medium, provided the original author(s) and source are credited.

\section{References}

Alexander M, Bhatt U, Walsh J, Timlin M, Miller J, Scott J (2004) The atmospheric response to realistic Arctic sea ice anomalies in an AGCM during winter. J Clim 17:890-905

Barnston AG, Smith TM (1996) Specification and prediction of global surface temperature and precipitation from global SST using CCA. J Clim 9:2660-2697

Boer GJ (2004) Long time-scale potential predictability in an ensemble of coupled climate models. Clim Dyn 23:29-44, doi: 10.1007/s00382-004-0419-8

Colman A, Davey M (1999) Prediction of summer temperature, rainfall and pressure in Europe from preceding winter North Atlantic ocean temperature. Int J Climatol 19:513-536

Collins M (2002) Climate predictability on interannual to decadal time scales: the initial value problem. Clim Dyn 19:671-692. doi:10.1007/s00382-002-0254-8

Collins M, Sinha B (2003) Predictability of decadal variations in the thermohaline circulation and climate. Geophys Res Lett 30(6). doi: 10.1029/2002G016504

Collins M, Botzet M, Carril AF, Drange H, Jouzeau A, Latif M, Masina S, Otteraa OH, Pohlmann H, Sorteberg A, Sutton R, Terray L (2006) Interannual to decadal predictability in the north atlantic: a multimodel-ensemble study. J Clim 19:1195-1203

Compo G P, Sardeshmukh PD (2004) Storm track predictability on seasonal and decadal scales. J Clim 17:3701-3720

Deser C, Magnusdottir G, Saravanan R, Philips A (2004) The effects of North Atlantic SST and sea ice anomalies on the winter circulation in CCM3. Part II: direct and indirect components of the response. J Clim 17:2160-2176

Dickson R, Meincke J, Malmberg SA (1988) The "Great Salinity Anomaly" in the northern North Atlantic, 1968-1982. Prog Oceanogr 20:103-151

Doblas-Reyes FJ, Pavan V, Stephenson DB (2003) The skill of multimodel forecasts of the wintertime North Atlantic oscillation. Clim Dyn 21:501-514. doi:10.1007/s00382-003-0350-4

Ellett DJ, Blindheim J (1992) Climate and hydrographic variability in the ICES area during the 1980s. ICES Mar Sci Symp 195:11-31

Fletcher CG, Saunders MA (2006) Winter North Atlantic oscillation hindcast skill: 1900-2001. J Clim 19:5762-5776

Frankignoul C, Friederichs P, Kestenare E (2003) Influence of Atlantic SST anomalies on the atmospheric circulation in the Atlantic-European sector. Annals Geophys 46(1):71-85

Friederichs P, Frankignoul C (2003) Potential seasonal predictability of the observed Euro-Atlantic atmospheric variability using SST forced ECHAM4-T42 simulations. Q J R Meteorol Soc 129(594):2879-2896

Griffies SM, Bryan K (1997) A predictability study of simulated North Atlantic multidecadal variability. Clim Dyn 13:459-487

Grumbine RW (1994) The thermodynamic predictability of sea-ice. J Glaciol 40(135):277-282

Haak H, Jungclaus J, Mikolajewicz U, Latif M (2003) Formation and propagation of great salinity anomalies. Geopys Res Lett 30(9):1473. doi:10.1029/2003GL017605

Hagemann S, Dümenil L (1998) A parameterisation of the lateral waterflow for the global scale. Clim Dyn 14(1):17-31

Hagemann S, Dümenil-Gates L (2003) Improving a subgrid runoff parameterisation scheme for climate models by the use of high resolution data derived from satellite observations. Clim Dyn 21(3-4):349-359

Häkkinen S (1999) A simulation of thermohaline effects of a Great salinity anomaly. J Clim 6:1781-1795

Hibler WD (1979) A dynamic-thermodynamic sea ice model. J Phys Oceanogr 9(4):815-846

Hirschi J, Marotzke J (2007) Reconstructing the meridional overturning circulation from boundary densities and the zonal wind stress. J Phys Oceanogr 37(3):743-763

Holland M, Bitz C (2003) Polar amplification of climate change in coupled models. Clim Dyn 21:221-232

Hurrell JW, Visbeck M, Busalacchi A, Clarke RA, Delworth TL, Dickson RR, Johns WE, Koltermann KP, Kushnir Y, Marshall D, Mauritzen C, McCartney MS, Piola A, Reason C, Reverdin G, Schott F, Sutton R, Wainer I, Wright D (2006) Atlantic climate variability and predictability: a CLIVAR perspective. J Clim 19:5100-5121

Jungclaus JH, Botzet M, Haak H, Keenlyside N, Lou JJ, Latif M, Marotzke J, Mikolajewicz U, Roeckner E (2006) Ocean circulation and tropical variability in the coupled model ECHAM5/MPI-OM. J Clim 19:3952-3972

Kanzow T, Cunningham SA, Rayner D, Hirschi JJM, Johns WE, Baringer MO, Bryden HL, Beal LM, Meinen CS, Marotzke J (2007) Observed flow compensation associated with the MOC at $26.5^{\circ} \mathrm{N}$ in the Atlantic. Science 317(5480):938-941

Keenlyside N, Latif M, Botzet M, Jungclaus J, Schulzweida U (2005) A coupled method for initializing El Nino southern oscillation forecasts using sea surface temperature. Tellus 57A:340-356

Koenigk T, Mikolajewicz U, Haak H, Jungclaus J (2006) Variability of Fram Strait sea ice export: causes, impacts and feedbacks in a coupled climate model. Clim Dyn 26:17-34. doi: 10.1007/s00382-005-0060-1

Koenigk T, Mikolajewicz U, Haak H, Jungclaus J (2007) Arctic freshwater export in the 20th and 21st century. J Geophys Res 112. doi: $10.1029 / 2006 J G 000274$ 
Kushnir Y, Robinson WA, Chang P, Robertson AW (2006) The physical basis for predicting Atlantic sector seasonal-to-interannual climate variability. J Clim 19(23):5949-5970. doi: 10.1175/JCLI3943.1

Kvamstö NG, Skeie P, Stephenson DB (2004) Large-scale impact of localized Labrador sea-ice changes on the North Atlantic Oscillation. Int J Climatol 24:603-612

Latif M, Collins M, Pohlmann H, Keenlyside N (2006) A review of predictability studies of Atlantic sector climate on decadal timescales. J Clim 19(23):5971-5987. doi:10.1175/JCLI3945.1

Lin H, Derome J (2003) The atmospheric response to North Atlantic SST anomalies in seasonal prediction experiments. Tellus 55A(3): 193-207

Lorenz EN (1963) Deterministic nonperiodic flow. J Atmos Sci 20:130-141

Magnusdottir G, Deser C, Saravanan R (2004) The effects of North Atlantic SST and sea ice anomalies on the winter circulation in CCM3. Part I: Main features and storm track characteristics of the response. J Clim 17(5):857-876

Marsland S, Haak H, Jungclaus J, Latif M, Roeske F (2003) The Max-Planck-Institute global ocean/sea ice model with orthogonal curvilinear coordinates. Ocean Model 5:91-127

Mu M, Duan WS, Wang JC (2002) The predictability problems in numerical weather and climate prediction. Adv Atmos Sci 19(2):191-204

Müller WA, Appenzeller C, Schär C (2005) Probabilistic seasonal prediction of the winter North Atlantic Oscillation and its impact on near surface temperature. Clim Dyn 24(2-3):213-226

Palmer TN (1993) Extended-Range Atmospheric Prediction and the Lorenz Model. Bull Am Meterol Soc 74:49-65

Peng S, Robinson WA, Li S, Hoerling MP (2005) Tropical Atlantic SST forcing of coupled North Atlantic seasonal response. J Clim 18(3):480-496. doi:10.1175/JCLI-3270.1

Pohlmann H, Botzet M, Latif M, Roesch A, Wild M, Tschuck P (2004) Estimating the decadal predictability of a coupled AOGCM. J Clim, Notes and Correspondence 4463-4472

Pozo-Vasquez D, Gamiz-Fortis SR, Tovar-Pescador J, Esteban-Parra MJ, Castro-Diez Y (2005) North Atlantic winter SLP anomalies based on the autumn ENSO state. J Clim 18(1):97-103

Quan XW, Webster PJ, Moore AM, Chang HR (2004) Seasonality in SST-forced atmospheric short-term climate predictability. J Clim 17:3090-3108

Reichler TJ, Roads JO (2003) The role of boundary and initial conditions for dynamical seasonal predictability. Nonlinear Processes Geophys 10:211-232
Rodwell MJ, Drevillon M, Frankignoul C, Hurrell JW, Pohlmann H, Stendel M, Sutton RT (2004) North Atlantic forcing of climate and its uncertainty from a multi-model experiment. Q J R Meteorol Soc 130(601):2013-2032. doi:10.1256/qj.03.207

Roeckner E, Baeuml G, Bonaventura L, Brokopf R, Esch M, Giorgetta M, Hagemann S, Kirchner I, Kornblueh L, Manzini E, Rhodin A, Schlese U, Schulzweida U, Tompkins A (2003) The atmosphere general circulation model ECHAM5, part 1: Model description. Max-Planck-Institut für Meteorologie, Report No. 349, pp 127

Saunders MA, Qian BD (2002) Seasonal predictability of the winter NAO from north Atlantic sea surface temperatures. Geophys Res Lett 29(2):2049-2052

Steele M, Morley R, Ermold W (2001) PHC: a global ocean hydrography with highquality Arctic Ocean. J Clim 14:20792087

Straus D, Shukla J, Paolino D, Schubert S, Suarez M, Pegion P, Kumar A (2003) Predictability of the seasonal mean atmospheric circulation during Autumn, Winter and Spring. J Clim 16(22):3629-3649

Tang YM, Kleeman R, Miller S (2006) ENSO predictability of a fully coupled GCM model using singular vector analysis. J Clim 19(14):3361-3377

Valcke S, Caubel A, Declat D, Terray L (2003) OASIS ocean atmosphere sea ice soil user's guide. CERFACS, Tech. Rep. TR/ GMGC/03/69, Toulouse, France, pp 85

Van den Dool HM, Peng P, Johannson A, Chelliah M, Shabbar A, Saha S (2006) Seasonal-to-decadal predictability and prediction of North American climate-the Atlantic influence. J Clim 19(23):6005-6024. doi:10.1175/JCLI3942.1

Van Oldenborgh GJ, Balmaseda MA, Ferranti L, Stockdale TN, Anderson DLT (2005a) Evaluation of atmospheric fields from the ECMWF seasonal forecasts over a 15 -year period. J Clim 18:3250-3269

Van Oldenborgh GJ (2005b) Comments on "Predictability of winter climate over the North Atlantic European region during ENSO events". J Clim 18:2770-2772

Zheng F, Zhu J, Zhang RH, Zhou GQ (2006) Improved ENSO forecasts by assimilating sea surface temperature observations into an intermediate coupled model. Adv Atmos Sci 23(4):615624. doi:10.1007/s00376-006-0615-z 